\title{
The Lack of Interest to do Counseling among Junior High School Students: Evaluation of Principals, Counselors, Teachers, and Peers Factors
}

\author{
Purwati Purwati ${ }^{1}$, Muhammad Japar, Hijrah Eko Putro \\ Universitas Muhammadiyah Magelang, Indonesia \\ Qbupurwati@ummgl.ac.id ${ }^{1}$
}

Article Information:

Received January 1, 2020

Revised April 1, 2020

Accepted April 10, 2020

Keywords: counselors; interest to do counseling; peers; principals; teachers

\begin{abstract}
This study departs from the limitations of research on how principals, counselors, teachers, and peers in inhibiting students' intention to do counseling. This study aims to determine how principals, counselors, teachers, and peers influence the lack of interest in student to do counseling. 162 students from six Junior High Schools in the city of Magelang, Indonesia were involved as participants after obtaining permission from the schools. The collected data is then analyzed using correlation and path analysis to see how the relationship and influence of principals, counselors, teachers, and peers on student counseling interests, and to see how the role of peers in mediating the relationship between principals with counselors and teacher with counselors. The school principals, counselors, and teachers become serious obstacles as they being categorized in high, while peers become factors in the medium category. Principals, teachers and peers contribute positively to the lack of interest in consulting to counselors. Principal factors and teachers contribute positively to peers. Peers are mediators in the principal's relationship with the counselor and the teacher's relationship with the counselor.
\end{abstract}

\section{INTRODUCTION}

Almost every schools provide counseling services for students (Bains \& Diallo, 2016) in order to help students develop optimally in terms of personal, social, learning, and career. Furthermore, Calaguas (2012) says that counseling services in education units are an inseparable part of the education system. However, sometimes many students unwittingly do not get this service from teachers or school counselors because of negligence on the part of the school itself (Greco et al., 2017).

On the other hand, students also often do not consider counseling services or to meet the counselors when they are faced with difficult situations (Daniel et al., 2010; Di Fabio \& Bernaud, 2008; Nota et al., 2005). This is due to the interest in counseling students who are classified as moderate (Maba \& Saputra, 2019). Moreover, Setiawan (2006) says that interest in counseling is low. She added, when experiencing problems, they prefer to tell their problems to friends or family rather than to counselors.

While many other studies discuss the interest of counseling from the point of view of personal, socio-cultural, and technical factors in service provision (Setiawan, 2006), in this paper, the authors will focus on how the roles of people in schools such as school principals, counselors, teachers, and peers at school influence student counseling interests.

How to cite:

E-ISSN:

Published by:
Purwati, P., Japar, M., \& Putro, H. (2020). The Lack of Interest to do Counseling among Junior High School Students: Evaluation of Principals, Counselors, Teachers, and Peers Factors. Islamic Guidance and Counseling Journal, 3(2). https://doi.org/10.25217/igcj.v3i2.737 2614-1566

Institut Agama Islam Ma'arif NU (IAIMNU) Metro Lampung 
There are not many studies that can be used as a reference when discussing the role of school stakeholders such as school principals, subject teachers, or peers toward students counseling interests. This is due to many studies that focus on personal, socio-cultural, and technical factors in service provision (Setiawan, 2006). Personal factors referring to the unwillingness to open up or admit that they are having problems (Masuda \& Boone, 2011), fears of stigma given to people who seek help (Vogel et al., 2007). The perception that they do not require any assistance, time constraints, and feels better to resolve the problems by their own self (Czyz et al., 2013).

Meanwhile, the socio-cultural factors, for instance, the values of collectivism are held tightly by people in Asian countries (Hofstede, 2001). Will be considered unfaithful if found someone asking for help from others that outside their group, furthermore, in some cases the action taken by someone is something that has been determined by their group (Hofstede, 2001). This tendency makes a person who lives in an environment with high collectivity will make him think repeatedly in acting because of the fear of damaging the good name of his group. Therefore, Komiya et al. (2000) say that feelings of shame, self-esteem and group are obstacles for someone to do counseling.

Technical problems in service delivery such as not knowing who the counselor will provide the service (North, 2002), counselor competence questioned by the counselee or prospective counselee (Kravitz et al., 2011), counseling that costs money only to meet the counselor (Barrett et al. ., 2008), difficulty arranging meeting times (Festinger et al., 2002), and people who think that ineffective counseling results in discomfort when meeting with counselors (Edlund et al., 2002).

From the various literatures described previously, the authors can draw a conclusion that the focus of the study in this paper has not been discussed by previous authors. So that studies conducted to evaluate the factors of principals, counselors, teachers, and peers at school are expected to fill the literature gap in the literatures of students counseling interests.

The purpose of this study is to determine the relationship and influence of school principals, counselors, subject teachers, and peers in the school in making students less interested in counseling. The hypotheses that the authors propose include 1) school principals, teachers, and peers positively predict student consultation interests to counselors, 2) school principals and teachers positively predict student consultation interests with peers, 3) peers are mediators in the relationship of principle with counselor, and (4 peers are mediators in the teacher's relationship with the counselor.

\section{METHODS}

162 students from six Junior High Schools spread across several regions in the city of Magelang. The schools have given permission for the authors to collect data. This research is use cross-sectional approach which means the data collected from participants only on one occasion thus there is no follow-up data.

Data collection is done using scale. The scale used was developed by the authors. The scale was created to reveal the reasons of lack of interest in counseling among students involving four aspects, including 1) the counselor aspect consisting of four indicators of personality, expertise, social competence, and work competency, 2) the principals, 3) teachers, and 4) peers at school. After going through the validity test, obtained 99 valid items with a correlation index $>0.349$ and reliability $>0.70$. The valid questionnaire items are then used for the data collection.

The authors conducted a correlation test between aspects then continued with path analysis using LISREL 8.8. The authors is guided by the steps of model fit test proposed by Ghozali (2017) by looking at p-value $>0.05$, Root Mean Square Error of Approximation $($ RMSEA $)<0.08$, Comparative Fit Index $(\mathrm{CFI})>0.90$, and Normed Fit Index (NFI) $>0.90$. 
If the model fit has not been fulfilled, the writer will make modifications by adding error relationships in some items with a large standardize residual or modification index (Yamin, 2014)

\section{RESULTS AND DISCUSSION}

The level of Mean, SD, and the correlation between variables in this study can be seen in the inter-correlation matrix in table 1 . Seen from the average factor counselors, principals, and subject teachers are barriers for the students to do counseling in the high category, while peers are in the medium category. Table 1 also shows that in general there is a positive correlation in all variables between counselors, principals, teacher, and peers. However, the counselors with peers shows the highest correlation. On the other hand, principals with peers show the lowest correlation.

\begin{tabular}{lccccc}
\hline Factors & Mean & SD & 1 & 2 & 3 \\
\hline 1. Counselor & 207.36 & 26.72 & & & \\
2. Principle & 24.27 & 4.77 & $0.68^{* *}$ & & \\
3. Teacher & 15.86 & 3.20 & $0.66^{* *}$ & $0.65^{* *}$ & \\
4. Peer & 33.25 & 6.47 & $0.74^{* *}$ & $0.52^{* *}$ & $0.60^{* *}$ \\
\hline
\end{tabular}

**. Correlation is significant at the 0.01 level (2-tailed)

Table 1. Inter-correlation Matrix

\begin{tabular}{lcccc}
\hline Direct effect & Coefficient & SE & t & R-square \\
\hline Peer - counselor & 1.908 & 0.239 & $8.001>1.96$ & 0.681 \\
Principle - counselor & 1.849 & 0.339 & $5.459>1.96$ & \\
Teacher - counselor & 1.406 & 0.541 & $2.597>1.96$ & \\
& & & & \\
Principle - peer & 0.307 & 0.110 & $2.792>1.96$ & 0.400 \\
Teacher - peer & 0.933 & 0.164 & $5.686>1.96$ & \\
\hline
\end{tabular}

Table 2. Direct effect prediction

\begin{tabular}{lccc}
\hline Indirect effect & Z Sobel & SE & P-Value \\
\hline Principle - peer - counselor & $2.63>1.96$ & 0.22 & $<0.05$ \\
Teacher - peer - counselor & $4.63>1.96$ & 0.38 & $<0.05$ \\
\hline
\end{tabular}

Tabel 3. Indirect effect prediction

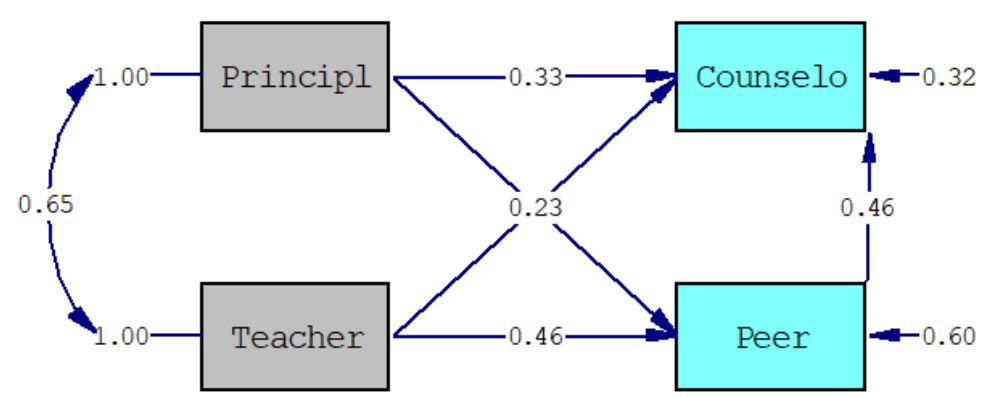

Figure 1. Model to predict principle, teacher, peer, and counselor in counseling interests

The model used in observing interactions between variables does not require modification because the model is perfectly fit. Based on information from table 2. That as predicted in hypothesis 1 , the principals, teachers, and peers positively predict counselors in reducing students' interest in consultation. Furthermore, as predicted in hypothesis 2, principals and teachers positively predict peers in reducing students' interest in consultation. Based on information from table 3, as predicted in hypotheses 3 and 4, peers are the mediators 
in the principals' relationship with the counselors and peers are the mediators in the teachers' relationship with the counselors.

The purpose of this study is to determine the role of school principals, counselors, peers, and teachers in student consulting interests. These objectives were divided into four hypotheses, including identifying 1) prediction of principals, teachers, and peers towards counselors, 2) predictions of school principals and teachers toward peers, 3) peer mediation in principals' relationship with counselors, and 4) mediation peers in the teachers' relationship with the counselors.

Based on the research findings, the factors that are the main obstacles for students to do counseling are counselors, principals, and teachers. In addition, principals, teachers, and peers positively predict counselors in reducing students' interest in consultation. This finding is in line with the results of North's (2002) findings that counselor characteristics and familiarity with service providers can be a barrier for students to consult. Lack of safeguarding the principle of confidentiality and trust factors is also a problem for students who want to consult with counselors (Biolcati et al., 2018). Furthermore, the majority of students with mental health problems or students who need help avoid formal forms of assistance provided by the schools (Husky et al., 2009).

Another obstacle that can cause students not to consult is the lack of policies that support the promotion of guidance and counseling services by school principals or teachers. Therefore, some research results suggest that schools should make policies that can promote mental health services early on (Greenberg, 2010; Vostanis et al., 2013).

Meanwhile, peers are in the medium category of being a barrier for the students to do counseling and the principal and teachers can predict peers to be a barrier to students to do counseling as well. Peers are indeed a more priority choice compared to getting formal assistance from mental health service providers or from schools (Asad \& Chreim, 2016; Naslund et al., 2016). Through peers they gain a sense of connectedness and acceptance because of the problems faced relative from the same perspective (Adame \& Leitner, 2008; Asad \& Chreim, 2016; Naslund et al., 2016). However, policies that are less precise than can make students even more reluctant to do counseling from the formal one. For example, by making a schedule for counseling students, those who come for counseling because they are scheduled can make the students receive stigma from their peers because they have done counseling (Yap et al., 2011). Particularly, in an Asian country like Indonesia which hold collectivism tightly (Hofstede, 2001). They will easily receive a stigma from their colleagues.

The results of this study indicate that school principals, counselors, and teachers are barriers those are included in the high category for students to be able to conduct consultations with the counselors. Another case with peers who are in the medium category. These factors influence each other and peers become mediators who can predict in the relationship of the principals with the counselors and the relationship of teachers with counselors. Thus, principals, counselors, and teachers must work together to build a good reputation for guidance and counseling services so that students who are deemed to need guidance and counseling services can provide support to meet with counselors to solve the problems.

The authors realize that this study has limitations. First, the instrument used is in the form of a self-report so the data obtained is very vulnerable to biases. Students' cognitive abilities greatly influence how they can understand each statement in the questionnaire. Second, the results of this study cannot be generalized to other types of samples, because they are very limited to junior high school levels and in a particular region only. Third, there is no analysis of how these factors differ when viewed from ethnicity, gender, grade, and age. Therefore, further studies are expected to use a mix method approach by utilizing qualitative data obtained from interviews or observations, involving a larger number and varied samples, 
and conducting data analysis by reviewing differences in ethnicity, sex, class, and age. However, the authors believe that this study has contributed to the literature with the findings mentioned earlier. as well as provide insights for the school stakeholders that they need to be together to promote the competency of the counselors and the reputation of the services.

\section{CONCLUSIONS}

The results showed that counselors, principals, and teachers were inhibitors with a high category, while peers were factors with a medium category. Principals, teachers and peers contribute positively to the lack of interest in student to do counseling. Principals and teachers contribute positively to peers. Peers are mediators in the principals' relationship with the counselor and the teachers' relationship with the counselor.

\section{ACKNOWLEDGMENTS}

The authors would like to thank all the schools and students who have deigned to become participants in this study. The authors are also sincere their gratitude to all parties who have provided support both materially and morally so that this study and article can be completed.

\section{AUTHOR CONTRIBUTION STATEMENTS}

Research instruments and data are stored by MJ. PP, MJ, and HEP jointly conducted research and wrote this article.

\section{REFERENCES}

Adame, A. L., \& Leitner, L. M. (2008). Breaking Out of the Mainstream: The Evolution of Peer Support Alternatives to the Mental Health System. Ethical Human Psychology and Psychiatry, 10(3), 146-162. https://doi.org/10.1891/1559-4343.10.3.146

Asad, S., \& Chreim, S. (2016). Peer Support Providers' Role Experiences on Interprofessional Mental Health Care Teams: A Qualitative Study. Community Mental Health Journal, 52(7), 767-774. https://doi.org/10.1007/s10597-015-9970-5

Bains, R. M., \& Diallo, A. F. (2016). Mental Health Services in School-Based Health Centers: Systematic Review. The Journal of School Nursing, 32(1), 8-19. https://doi.org/10.1177/1059840515590607

Barrett, M. S., Chua, W.-J., Crits-Christoph, P., Gibbons, M. B., \& Thompson, D. (2008). Early withdrawal from mental health treatment: Implications for psychotherapy practice. Psychotherapy: Theory, Research, Practice, Training, 45(2), 247-267. https://doi.org/10.1037/0033-3204.45.2.247

Biolcati, R., Palareti, L., \& Mameli, C. (2018). What Adolescents Seeking Help Teach us About a School-Based Counseling Service. Child and Adolescent Social Work Journal, 35(1), 45-56. https://doi.org/10.1007/s10560-017-0503-7

Calaguas, G. M. (2012). Academic achievement and school ability: Implications to guidance and counseling programs. Researchers World, 3(2), 49. Retrieved from Google Scholar

Czyz, E. K., Horwitz, A. G., Eisenberg, D., Kramer, A., \& King, C. A. (2013). Self-reported Barriers to Professional Help Seeking Among College Students at Elevated Risk for Suicide. Journal of American College Health: $J$ of ACH, 61(7), 398-406. https://doi.org/10.1080/07448481.2013.820731

Daniel, B., Taylor, J., \& Scott, J. (2010). Recognition of neglect and early response: Overview of a systematic review of the literature. Child \& Family Social Work, 15(2), 248-257. https://doi.org/10.1111/j.1365-2206.2009.00670.x 
Di Fabio, A., \& Bernaud, J.-L. (2008). The help-seeking in career counseling. Journal of Vocational Behavior, 72(1), 60-66. https://doi.org/10.1016/j.jvb.2007.10.006

Edlund, M. J., Wang, P. S., Berglund, P. A., Katz, S. J., Lin, E., \& Kessler, R. C. (2002). Dropping out of mental health treatment: Patterns and predictors among epidemiological survey respondents in the United States and Ontario. The American Journal of Psychiatry, 159(5), 845-851. https://doi.org/10.1176/appi.ajp.159.5.845

Festinger, D. S., Lamb, R. J., Marlowe, D. B., \& Kirby, K. C. (2002). From telephone to office: Intake attendance as a function of appointment delay. Addictive Behaviors, 27(1), 131-137. https://doi.org/10.1016/S0306-4603(01)00172-1

Ghozali, I. (2017). Structural equations model concepts and application with Amos 24 program. Agency Publiher UNDIP. Retrieved from Google Scholar

Greco, A. M., Guilera, G., \& Pereda, N. (2017). School staff members experience and knowledge in the reporting of potential child and youth victimization. Child Abuse \& Neglect, 72, 22-31. https://doi.org/10.1016/j.chiabu.2017.07.004

Greenberg, M. T. (2010). School-based prevention: Current status and future challenges. Effective Education, 2(1), 27-52. https://doi.org/10.1080/19415531003616862

Hofstede, G. (2001). Culture's consequences: Comparing values, behaviors, institutions and organizations across nations. Sage publications. Retrieved from Google Scholar

Husky, M. M., McGuir, L., Flynn, L., Chroswski, C., \& Olfson, M. (2009). Correlates of help-seeking behavior among at-risk adolescents. Child Psychiatry Human Development, 40, 15-24. Retrieved from Google Scholar

Komiya, N., Good, G. E., \& Sherrod, N. B. (2000). Emotional openness as a predictor of college students' attitudes toward seeking psychological help. Journal of Counseling Psychology, 47(1), 138-143. https://doi.org/10.1037/0022-0167.47.1.138

Kravitz, R. L., Paterniti, D. A., Epstein, R. M., Rochlen, A. B., Bell, R. A., Cipri, C., Fernandez y Garcia, E., Feldman, M. D., \& Duberstein, P. (2011). Relational barriers to depression help-seeking in primary care. Patient Education and Counseling, 82(2), 207-213. https://doi.org/10.1016/j.pec.2010.05.007

Maba, A. P., \& Saputra, A. A. (2019). Intention to Seek Counseling Among Indonesian Students: Examining the Impact of Social Anxiety and Loneliness. Islamic Guidance and Counseling Journal, 2(2), 40-48. https://doi.org/10.25217/igcj.v2i2.434

Masuda, A., \& Boone, M. S. (2011). Mental Health Stigma, Self-Concealment, and HelpSeeking Attitudes among Asian American and European American College Students with No Help-Seeking Experience. International Journal for the Advancement of Counselling, 33(4), 266-279. https://doi.org/10.1007/s10447-011-9129-1

Naslund, J. A., Aschbrenner, K. A., Marsch, L. A., \& Bartels, S. J. (2016). The future of mental health care: Peer-to-peer support and social media. Epidemiology and Psychiatric Sciences, 25(2), 113-122. https://doi.org/10.1017/S2045796015001067

North, P. (2002). Students under stress-So why are they not queuing up for counselling? Association for University and College Counselling Journal, Special Issue, 33-35. Retrieved from Google Scholar

Nota, L., Soresi, S., Solberg, S. H., \& Ferrari, L. (2005). Promoting Vocational Development: Methods of Intervention and Techniques Used in the Italian Context. International Journal for Educational and Vocational Guidance, 5(3), 271-279. https://doi.org/10.1007/s10775-005-3602-5

Setiawan, J. L. (2006). Willingness to seek counselling, and factors that facilitate and inhibit the seeking of counselling in Indonesian undergraduate students. British Journal of Guidance \& Counselling, 34(3), 403-419. https://doi.org/10.1080/03069880600769654

Vogel, D. L., Wade, N. G., \& Hackler, A. H. (2007). Perceived public stigma and the willingness to seek counseling: The mediating roles of self-stigma and attitudes toward 
counseling. Journal of Counseling Psychology, 54(1), 40. https://doi.org/10.1037/00220167.54.1.40

Vostanis, P., Humphrey, N., Fitzgerald, N., Deighton, J., \& Wolpert, M. (2013). How do schools promote emotional well-being among their pupils? Findings from a national scoping survey of mental health provision in English schools. Child and Adolescent Mental Health, 18(3), 151-157. https://doi.org/10.1111/j.1475-3588.2012.00677.x

Yamin, S. (2014). Rahasia olah data Lisrel. Mitra Wacana Media. Retrieved from Google Scholar

Yap, M. B. H., Wright, A., \& Jorm, A. F. (2011). The influence of stigma on young people's help-seeking intentions and beliefs about the helpfulness of various sources of help. Social Psychiatry and Psychiatric Epidemiology, 46(12), 1257-1265. https://doi.org/10.1007/s00127-010-0300-5 